\title{
PTERALIA OF THE PALEOZOIC INSECT ORDERS PALAEODICTYOPTERA, MEGASECOPTERA AND DIAPHANOPTERODEA (PALEOPTERA)*
}

\author{
By Jarmila Kukalova-Peck \\ Department of Geology, Carleton University \\ Ottawa, Ontario, Canada
}

For an understanding of insect evolution the structure of the wing base is of major significance. However, the fossil record of pteralia in extinct orders is extremely scanty. This paper is concerned with the wing bases of certain Paleozoic Paleoptera, namely, Palaeodictyoptera, Megasecoptera and Diaphanopterodea from the Upper Carboniferous (Namurian) of Czechoslovakia, the Upper Carboniferous (Stephanian) of France, and the Lower Permian of Czechoslovakia and Kansas. Independently of the Neoptera, the Diaphanopterodea acquired the ability to flex the wings backwards over the abdomen. In this respect, the order is of special interest, and an attempt is made here to compare the pteralia of the Diaphanopterodea with those of extant Ephemeroptera.

Our present knowledge of the wing base in Paleozoic Paleoptera is restricted to the axillary plate of several palaeodictyopteran adults (Kukalova, 1960, 1969-70), and palaeodictyopteran nymphs (Wootton, I972; Sharov, I97I) [See figures I, 2 and 4]. Recently, the wing base has been described in the Diaphanopterodea, Family Elmoidae (Kukalova-Peck, 1974) (fig. 8). In the present paper, the axillary plates in Martynoviidae and Asthenohymenidae of the Order Diaphanopterodea are included, and for the first time the axillary sclerites in Megasecoptera are described.

The interpretation and terminology of the pteralia in extinct Paleoptera are necessarily dependent upon the detailed functional morphology of extant Ephemeroptera and Odonata. At the same time, the wing base structures found in extinct orders provide an evolutionary view and might be helpful in unraveling the enigmatic archi-

*This research has been aided in part by a Publication Grant from Carleton University and in part by a National Science Foundation Grant, GB 39720, F. M. Carpenter, Principal Investigator, Harvard University. I am deeply indebted to Dr. Carpenter for his assistance in finding specimens and for placing them at my disposal at the Museum of Comparative Zoology. I also wish to express my sincere gratitude to Dr. R. J. Wootton (University of Exeter, England) and Dr. P. A. Adams (California State University at Fullerton) for their valuable critical comments.

Manuscript received by the editor December 15, 1974. 


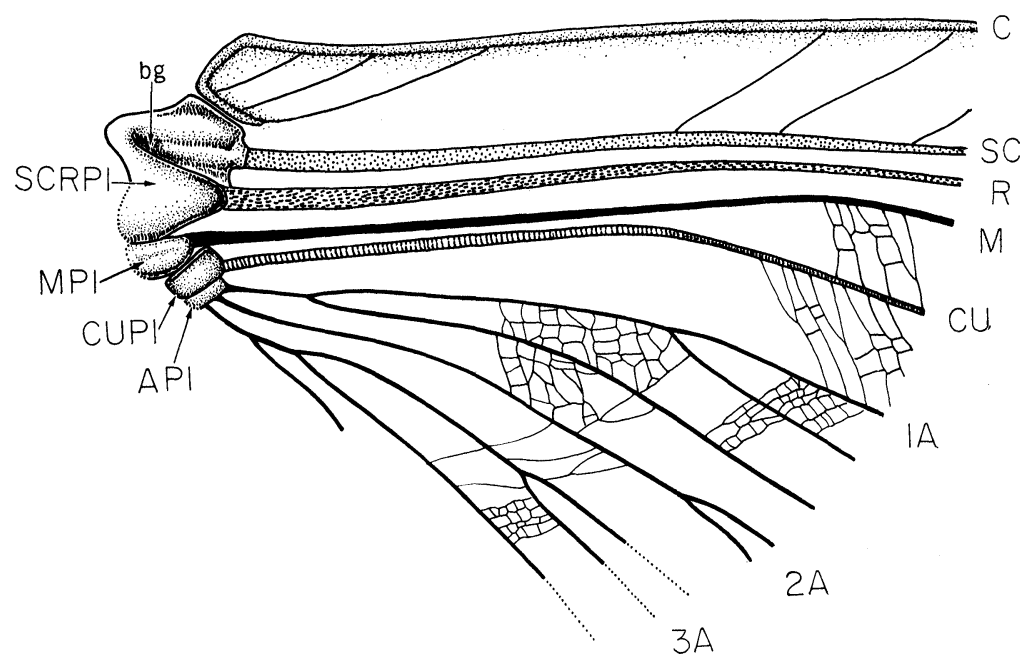

Fig. 1. Partially fused axillary plate of Boltopruvostia nigra (Palaeodictyoptera, Homoiopteridae). Enlarged base of fore wing. Redrawn from Kukalova, 1960. APl - anal plate; bg - basal groove; CuPl cubital plate; MPl - median plate; ScRPl - subcosto-radial plate. Upper Namurian, Czechoslavakia.

tecture of extant Paleoptera. In the Odonata, the thorax and pteralia have been discussed in detail by Tannert (I958), Neville (I960), and Hatch (1966), but interpretation of these structures is still subject to debate. The axillary plate is considered either as the fused radio-anal plate, or as a compound structure, with the radio-anal plate, axillary sclerites, and subalare incorporated. However, the wings of the Odonata are highly specialized and possess many unique features and therefore are less suited for comparison with Paleozoic orders than the more primitive wings of the Ephemeroptera. The pteralia in Ephemeroptera have been recently studied by Brodskyi (I970), Matsuda (1970), and Tsui and Peters (1972) (fig. 5), but the axillary plate was not described in functional terms; it was mostly referred to as "median plate". In this paper, the terminology is derived from Tannert's ( 1958 ) account on the Odonata and the respective axillary plates are called by the terms of incorporated basal plates of the veins. Since the fossil specimens do not contribute to our knowledge of whether the other pteralia are fused with the axillary plate, this problem should be considered as fully open to future emendations based upon a detailed study of functional morphology. 


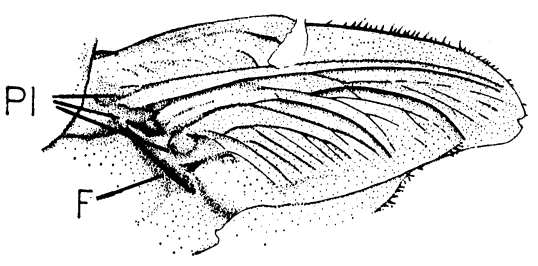

Fig. 2. Palaeodictyopteran nymphal wing pad with partially separate basal plates. Idoptilus onisciformis (Graphiptilidae). After Wootton, 1972. F-deep furrow along the thorax; Pl-basal plates. Westphalian, England.

\section{Palaeodictyoptera AND Ephemeroptera}

In the most primitive, yet unknown, Paleoptera all main veins probably originated at the wing base from the separate basal plates. In the process of evolution, the basal plates gradually became fused. The intermediate stage of partial fusion is documented in the primitive palaeodictyopteron, Boltopruvostia nigra (Namurian $\mathrm{C}$ of Czechoslovakia, fig. I). In this species the subcostal and radial plates are fully grown together (forming the subcosto-radial plate), the median plate is separate, and the cubital plate is fused with the small anal plate (forming the cubito-anal plate). The partially separated basal plates are also indicated in the wing pad of the nymph Idoptilus onisciformis (Wootton 1972, Westphanian of England) (fig. 2).

Within the evolutionary history of Palaeodictyoptera, full fusion of the plates was acquired in the more specialized forms. Basal plates fused together into a single subcosto-anal plate but still retaining an indication of individual outlines, have been found in Moravia convergens (Lower Permian of Czechoslovakia, fig. 3). In Palaeodictyoptera from the Upper Carboniferous of France (fig. 4), the subcosto-anal basal plate is fully fused and its subcostal part becomes reduced in size.

In the primitive Ephemeroptera (Siphlonuridae, fig. 6), the costal brace in the fore wing starts at the anteroproximal angle of the axillary plate; in the hind wing, it sometimes starts from a transverse elevation on the axillary plate, forming a convex hook directed against the stem of $M$. The costal brace is, in all probability, homologous to the postcostal vein of Palaeodictyoptera (fig. ${ }_{4} \mathrm{~B}, \mathrm{pv}$ ), plus the cross vein between $\mathrm{Sc}$ and $\mathrm{R}$. The base of ephemeropteran wings is weakly sclerotized and the stems of the main veins adjacent to the axillary plate are mostly not discernible. However, if the vein stems 
in primitive mayflies are thoroughly examined, their connection with the axillary plate can be traced. This is true in many Siphlonuridae, especially in the hind wings (fig. 6B). In the fore wing of Siphlonurus mirus (fig. 6A), the axillary plate is domed in the middle. At the anteroproximal angle, there is a short groove, which is also present in Palaeodictyoptera (fig. I, 3). Expanded stems of Sc and R (which might in this Siphlonurus be represented by the fused $\mathrm{R}+\mathrm{M}+\mathrm{Cu}$ stems) meet at a suture and clearly penetrate the axillary plate. In the hind wing of the same species, the groove at the anteroproximal angle is reduced to a small pit. $\mathrm{R}$ is located at the anterior part of the dome and is closely followed by the short stem of $M$, from which $\mathrm{MA}$ and MP diverge almost immediately. The short stem of $\mathrm{Cu}$

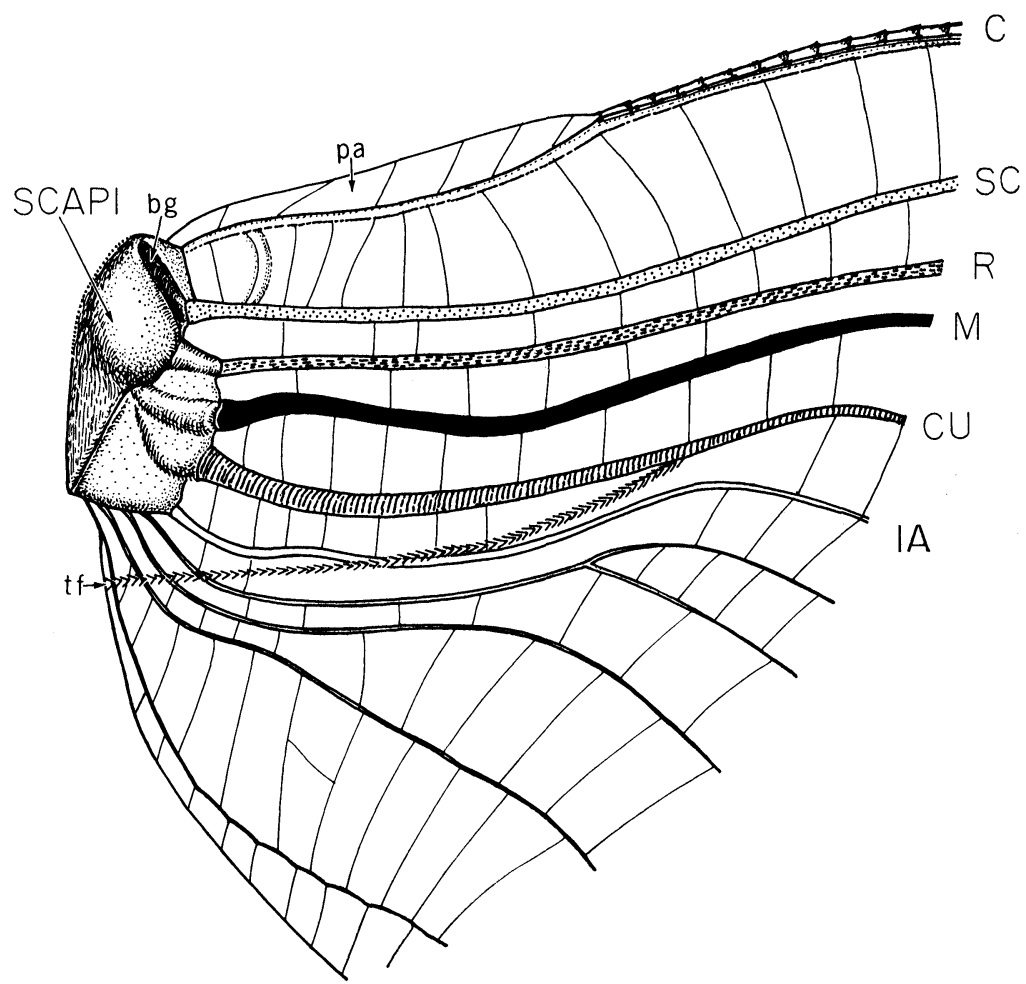

Fig. 3. Fused subcosto-anal plate of Moravia convergens (Palaeodictyoptera, Calvertiellidae). Enlarged base of the fore wing. Original. bg basal groove; pa - precostal area; ScAPl - subcosto-anal plate; tf transverse furrow. Lower Permian, Czechoslovakia. 
meets $\mathrm{MP}$ and instantly splits into $\mathrm{CuA}$ and $\mathrm{CuP}$. As described above, all main veins, with the exception of the anal veins, start in the hind wing directly and separately from the domed part of the axillary plate, as in more advanced Palaeodictyoptera (fig. 4).

The main difference between the axillary region of the Palaeodictyoptera and that of the Ephemeroptera is in the attachment of the anal veins. In the Palaeodictyoptera, the anal veins probably always originated directly from the subcosto-anal plate (figs. 3, 4), or the anal plate was closely attached to the cubital plate (fig. I). The anal area in Palaeodictyoptera is often crossed by diverse convex ridges, which are sometimes V-shaped (Homaloneura, Kukalova 1969), and by transverse grooves (figs. 3, 4A), or the anal veins start from a cuticular thickening (Dunbaria, Kukalova-Peck 197I). As pointed out by Wootton (1974, personal communication), these structures are in the place of the anal brace of Ephemeroptera. In the primitive mayflies, the anal veins start at the anal brace, which is basally attached to a small plate, separated from the large axillary plate. It seems possible that while the axillary plate originated by fusion of the subcosto-cubital plates, the anal plate stayed detached. This condition is partially reminiscent of Diaphanopterodea and Megasecoptera, as will be shown below. The anal brace in Ephemeroptera is followed, both anteriorly and posteriorly, by two concave furrows. By location and, very probably, by function for flight, the furrows may be compared with the concave transverse furrow, crossing the anal area in almost all Palaeodictyoptera (figs. 3, 4A).

The weak sclerotization of the axillary plate in Ephemeroptera and the vanishing of the adjacent stems are probably the changes which
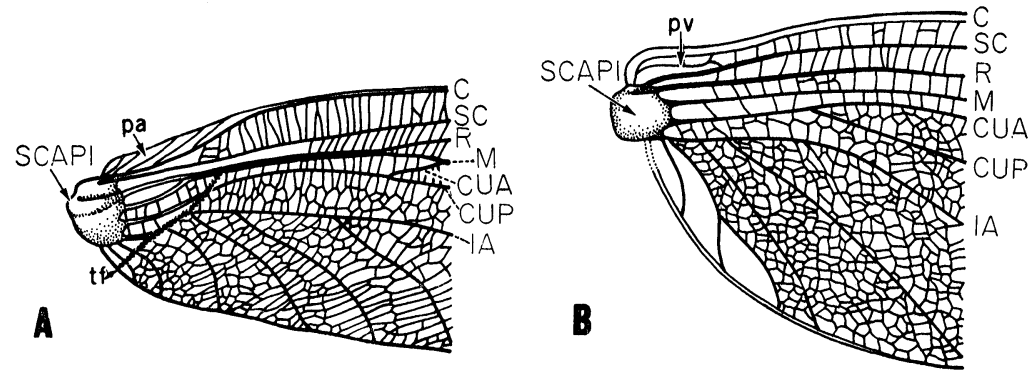

Fig. 4. Fused subcosto-anal plates of Palaeodictyoptera. A. Dictyoptilus sepultus (Eugereonidae), enlarged base of the fore wing. B. Stenodictya parisiana (Dictyoneuridae), enlarged base of the hind wing. After Kukalova, 1970. pa - precostal area; pv - postcostal vein; ScAPl - subcosto-anal plate; tf - transverse furrow. Upper Carboniferous, France. 
occurred later in evolution. This conclusion is supported by the morphology of primitive Permian mayfly families, the Protereismatidae and the Misthodotidae. In both, the stems of main veins were strong, reaching the wing base, and the anal brace was less pronounced than in extant mayflies (fig. 7). It should be noted that the adult life span in Permian Ephemeroptera was probably longer than in Recent species; the presence of large and apparently fully functional mouthparts in the adult Permian Misthodotidae (Tschernova, I965) is very suggestive that these particular mayflies, at least, were active feeders. Flight was presumably important in obtaining food, as well as in courtship activities.

According to Brodskyi (1970), the second axillary sclerite in Recent Ephemeroptera is firmly fused with the axillary plate, although this opinion is not shared by some other specialists; the schematic figure of the axillary region in extant mayflies (Leptophlebiidae) in the interpretation of Tsui and Peters (1972) is shown in figure 5. In the fossil material described, no remnants of the axillary region have been mentioned so far.

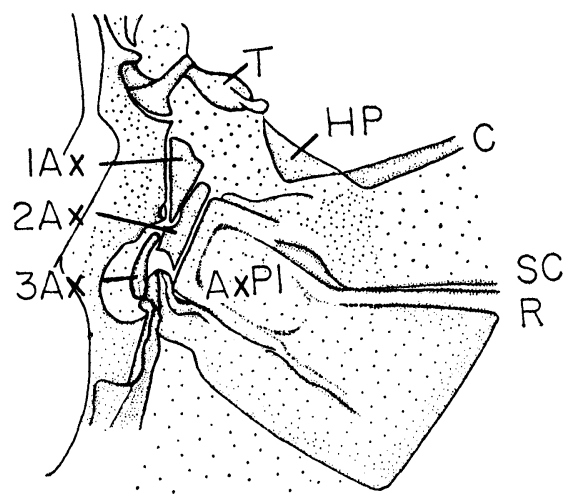

Fig. 5. Axillary region of fore wing of ephemeropteron, Aprionyx tricuspidatus (Leptophlebiidae, adult male). After Tsui and Peters, 1972. $\mathrm{AxPl}$ - axillary plate; $\mathrm{Ax} 1,2,3$-axillary sclerites; $\mathrm{HP}$-humeral plate; T-tegula. Recent.

\section{DiAPHANOPTERODEA}

The Diaphanopterodea have mouthparts, genitalia and wing venation pattern very similar to those of Palaeodictyoptera, from the primitive forms of which they were probably derived (Carpenter, 

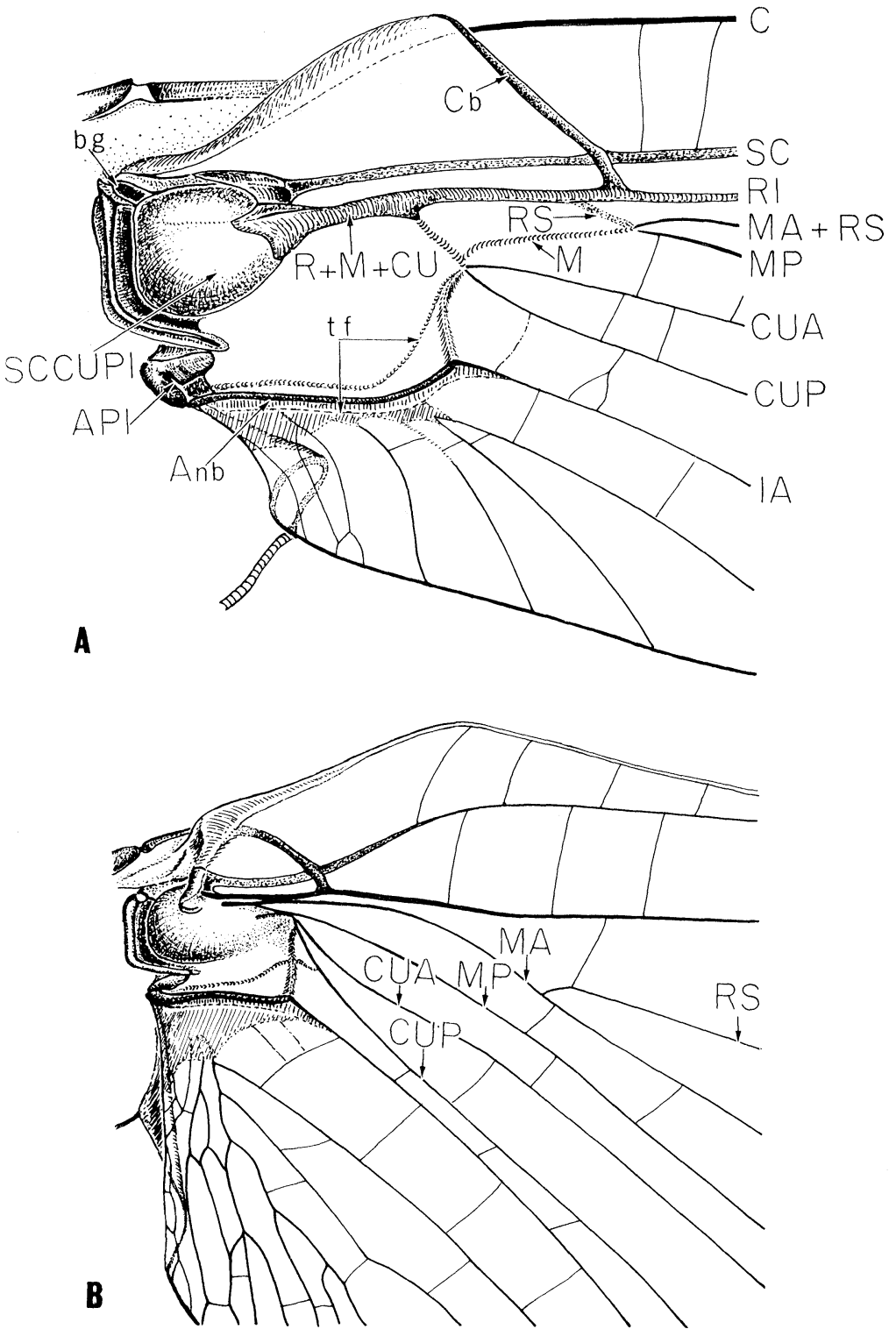

Fig. 6. Subcosto-cubital plate of ephemeropteron, Siphlonurus mirus (Siphlonuridae). A. Fore wing; B. Hind wing. Original. Anb - anal brace; $\mathrm{APl}$ - anal plate; bg-basal groove; $\mathrm{Cb}$ - costal brace; ScCuPl - subcosto-cubital plate; tf - transverse furrow. Recent. 
1963). In comparison with the average size of Palaeodictyoptera, they are much smaller and they developed the ability to flex the wings backwards over the abdomen. The axillary plate of the wing base and the basal fold were recently described by Kukalova-Peck (1974) in Permodiapha carpenteri of the family Elmoidae (fig. 8A). Here, the axillary plate is compared with that of the related family Martynoviidae as preserved in Martynovia protohymenoides (specimen No. 460o, Museum of Comparative Zoology, Harvard University) from the Lower Permian of Kansas (fig. 8B).

In both forms, the general patterns of the wing base structure are similar. The larger part of the axillary plate in Martynovia is formed by the fused medio-cubital plate, or perhaps by the cubital plate itself. Different is the development of the anal plate, which is distinctly outlined and two-lobed, located anteriorly to the basal fold. The anal plate is firmly connected by the anterior margin with the axillary plate. The basal fold encircles the axillary plate anteriorly and distally and separates it from the sclerotized region, extending between $\mathrm{CuP}$ and the posterior wing margin (fig. $8 \mathrm{~B}, \mathrm{~S}$ ). The axillary plate in both Martynovia and Permodiapha is obliquely crossed by a convex strut, which perhaps participated in the folding of the wings. The incompletely preserved axillary sclerite contacts

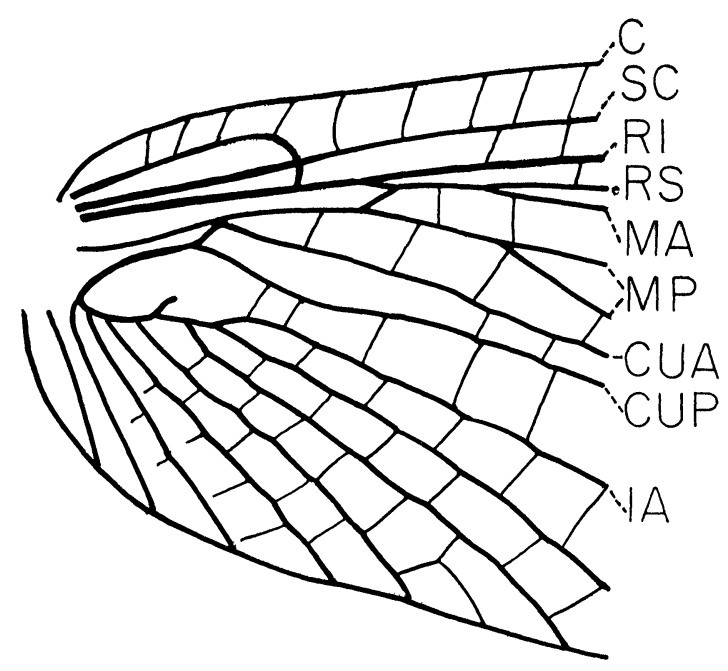

Fig. 7. Fore wing base of Permian mayfly, Protereisma permianum (Protereismatidae). After Carpenter, 1933. Lower Permian, Kansas. 

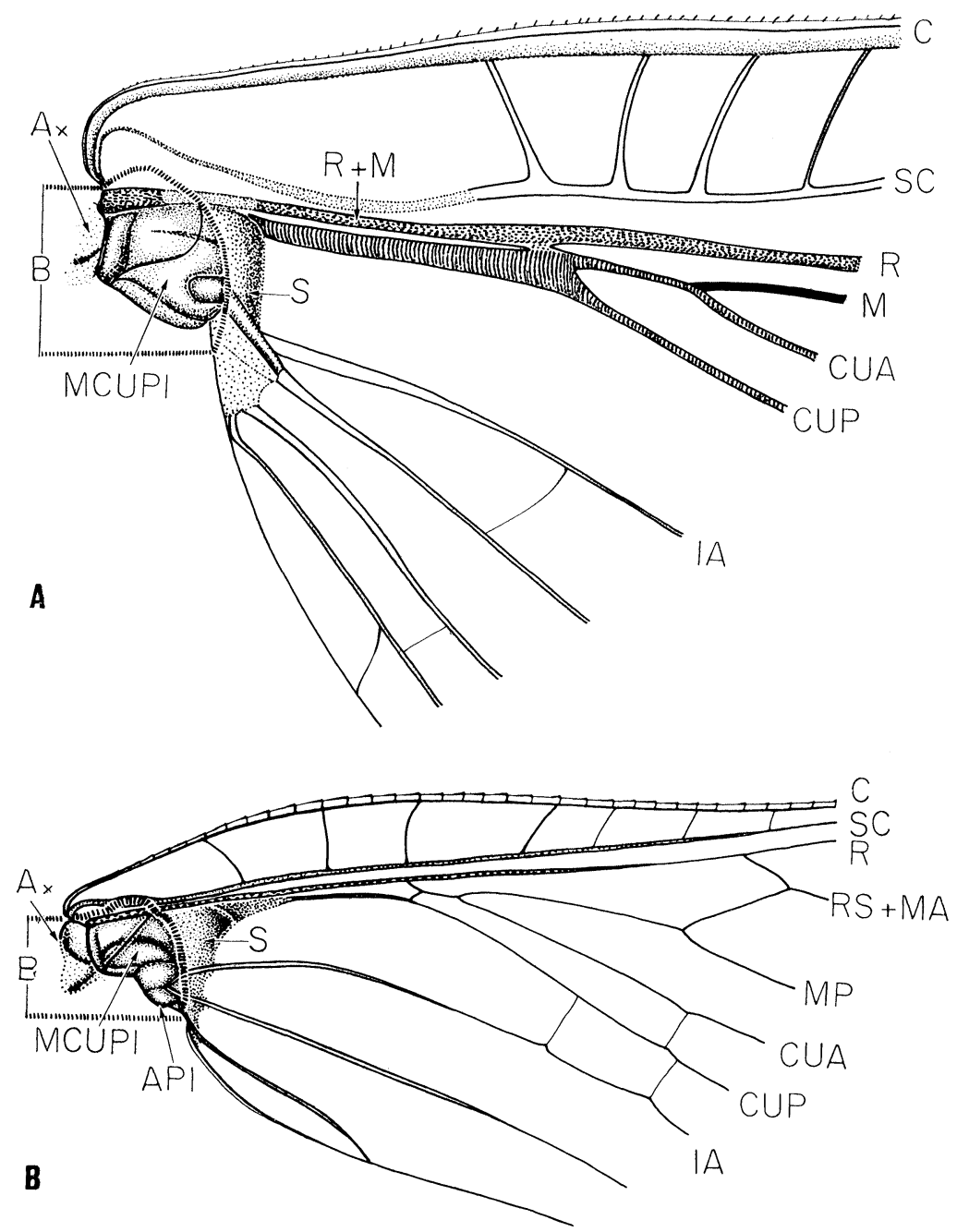

Fig. 8. Medio-cubital plate of Diaphanopterodea. A. Permodiapha carpenteri (Elmoidae), hind wing. After Kukalova-Peck, 1974. B. Martynovia protohymenoides (Martynoviidae), fore wing. Original. APl anal plate; $\mathrm{Ax}$ - axillary sclerite; $\mathrm{B}$-basal fold; $\mathrm{MCuPl}$-mediocubital plate; S-sclerotized region. Lower Permian, Czechoslovakia and Kansas. 


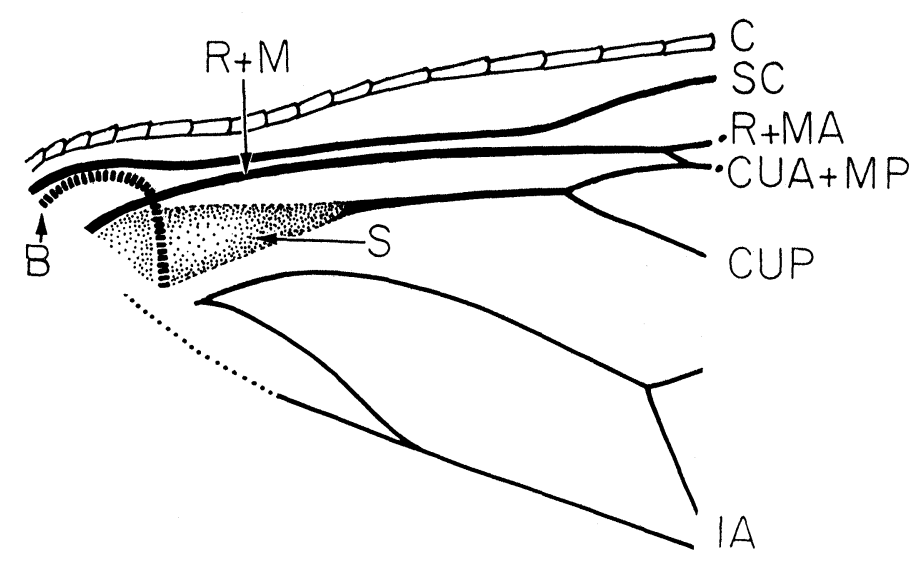

Fig. 9. Incomplete wing base of Asthenohymen dunbari (Diaphanopterodea, Asthenohymenidae). Fore wing. Original. B-basal fold; Ssclerotized region. Lower Permian, Kansas.

with the proximal margin of the axillary plate and with $\mathrm{R}$. It is in the position of $2 \mathrm{Ax}$ in Recent Ephemeroptera (sensu Tsui and Peters 1972, fig. 5).

In Asthenohymenidae, the incompletely preserved wing base, including only the basal fold and part of the sclerotized region, is known. The structure of the wing base, as preserved in Asthenohymen dunbari (specimen No. 3835, Museum of Comparative Zoology, fig. 9) seems to be basically similar to that of Martynovia and Permodiapha.

The fused axillary plate of Diaphanopterodea is homologous only to the posterior part of the subcosto-anal plate of Palaeodictyoptera. The subcostal, radial, and possibly also the median basal plates became completely reduced, perhaps in connection with narrowing of the wing base, coalescence of veins and with acquisition of wing folding ability.

\section{Megasecoptera}

The Megasecoptera and Palaeodictyoptera have very similar mouthparts, genitalia and wing venation pattern, and undoubtedly developed from common ancestral stock. The Megasecoptera differed, according to our previous understanding, only in the shape of the wings and in the more pronounced crowding of $\mathrm{Sc}$ and $\mathrm{R}$ towards the costal margin. However, the study of the wing base has revealed a 


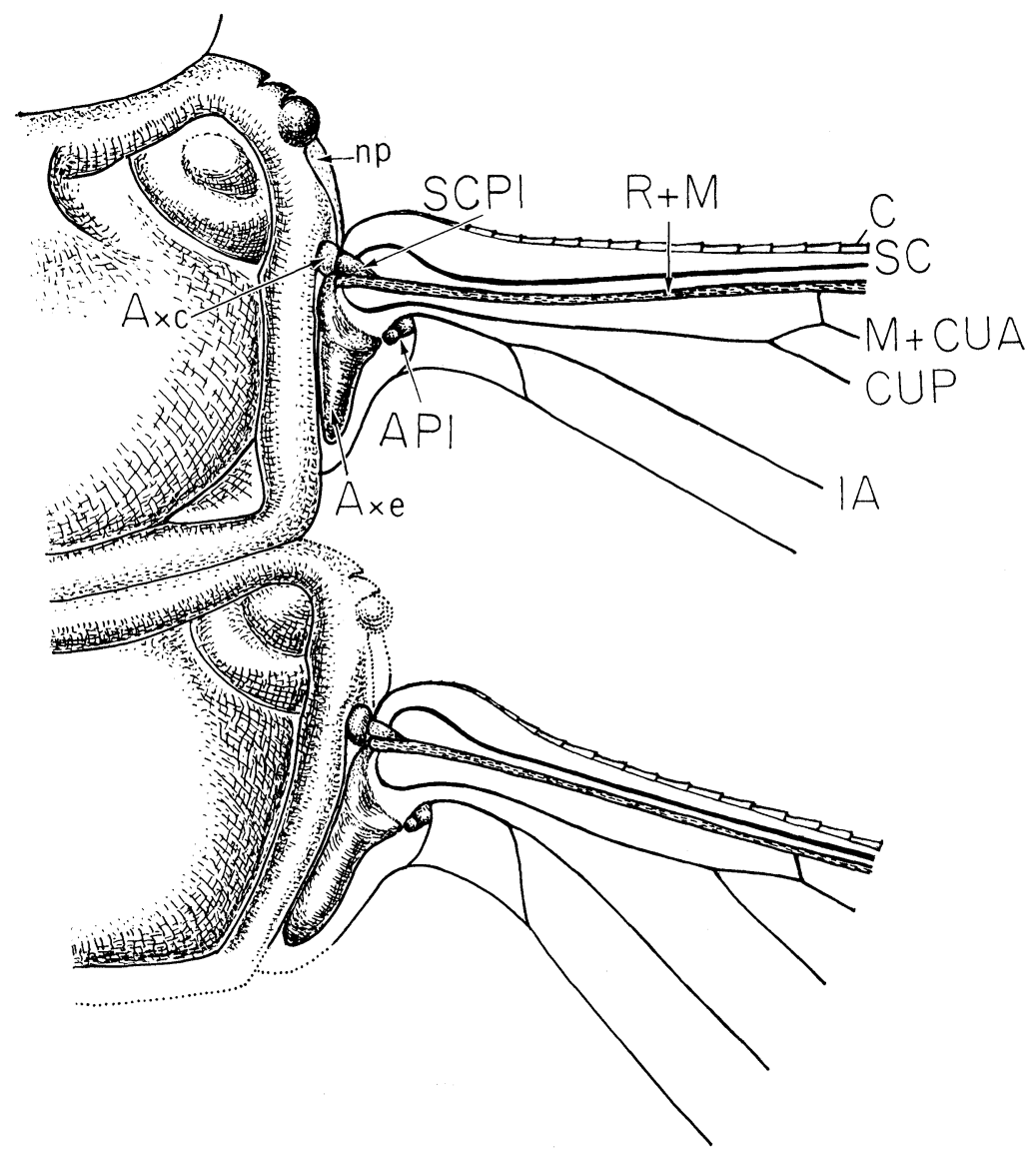

Fig. 10. Pteralia of Protohymen permianus (Megasecoptera, Protohymenidae). Enlarged base of the fore and hind wings. Original. AP1 - anal plate; Axc-convex axillary sclerite; Axe-elongated axillary sclerite; $\mathrm{np}$ - narrow plate; $\mathrm{ScPl}$ - subcostal plate. Lower Permian, Kansas.

major difference in the pteralia, not only with respect to Palaeodictyoptera, but also to all other paleopterous orders.

The well preserved wing bases with axillary sclerites were found in specimens of two comparatively small species: Protohymen permianus (specimen No. 3060) and Protohymen readi (holotype No. 3258), in the Museum of Comparative Zoology. Since the structures in both specimens are similar, only the wing bases of Protohymen permianus, which is better preserved, are described (fig. 10). 
Towards the base, the wing narrows markedly in the posterior part, while the anterior margin remains almost straight. Shortly before the base, the posterior margin curves posteriorly to form a prolonged axillary lobe parallel with the tergal margin. The serrated costa is attached at the very base to a long narrow plate on the lateral margin of the tergum. This plate is connected anteriorly with a prominent, darkly colored lobe. The subcosta is convexly bent near the base. Both costa and subcosta terminate on a triangular, highly convex basal plate, which is posteriorly connected to $R+M$ and proximally to the small, convex axillary sclerite. This is associated with the tergal margin, the basal plate, the costa, the narrow plate on the tergum, and the anterior arm of the large elongated sclerite. The cubitus is concavely bent towards the very end of $\mathrm{R}$ shortly before the base, so that it creates the mirror image of the subcosta. The anal vein originates from a small anal plate, which is divided by a perpendicular suture into two small equal sections. The anal plate is directed obliquely and posteriorly against the posterior arm of a large, anteroposteriorly elongated sclerite. This closely contacts the tergum along almost its entire proximal margin. The elongated sclerite is highly convex posteriorly from the level of the end of the anal plate. In the anterior, flatter part, the axillary sclerite divides into two arms. The proximal arm is longer and slightly bent to attach to $R+M$ and to the small axillary sclerite; the distal arm is shorter and directed to connect the curved end of the anal plate. This sclerite is markedly larger in the hind wing.

The megasecopteran pteralia, as described above (figs. IO, I I), are so highly specialized that homology at our present level of knowledge is nearly impossible. The narrow plate laterally on tergum (np) and the elongate sclerite (Axe) as well seem to be compound structures in which several elements might be incorporated. The small convex sclerite $(\mathrm{Axc})$ is approximately in the position of $\mathrm{I} A \mathrm{x}$ of Ephemeroptera (sensu Tsui and Peters I972; fig. 5). The little basal plate $(\mathrm{ScPl})$ at the beginning of $\mathrm{Sc}$ is perhaps homologous to the subcostal basal plate of hypothetical primitive Paleoptera. The highly specialized character of megasecopteran pteralia shows that the construction of the wing attachment in Paleoptera was even more varied and diverse than it has been assumed. However, it should be taken into consideration that the pteralia of Protohymen may not be typical for the whole order Megasecoptera because of its relatively small size. In small insects, reduction and other modification of axillary sclerites sometimes occur. 


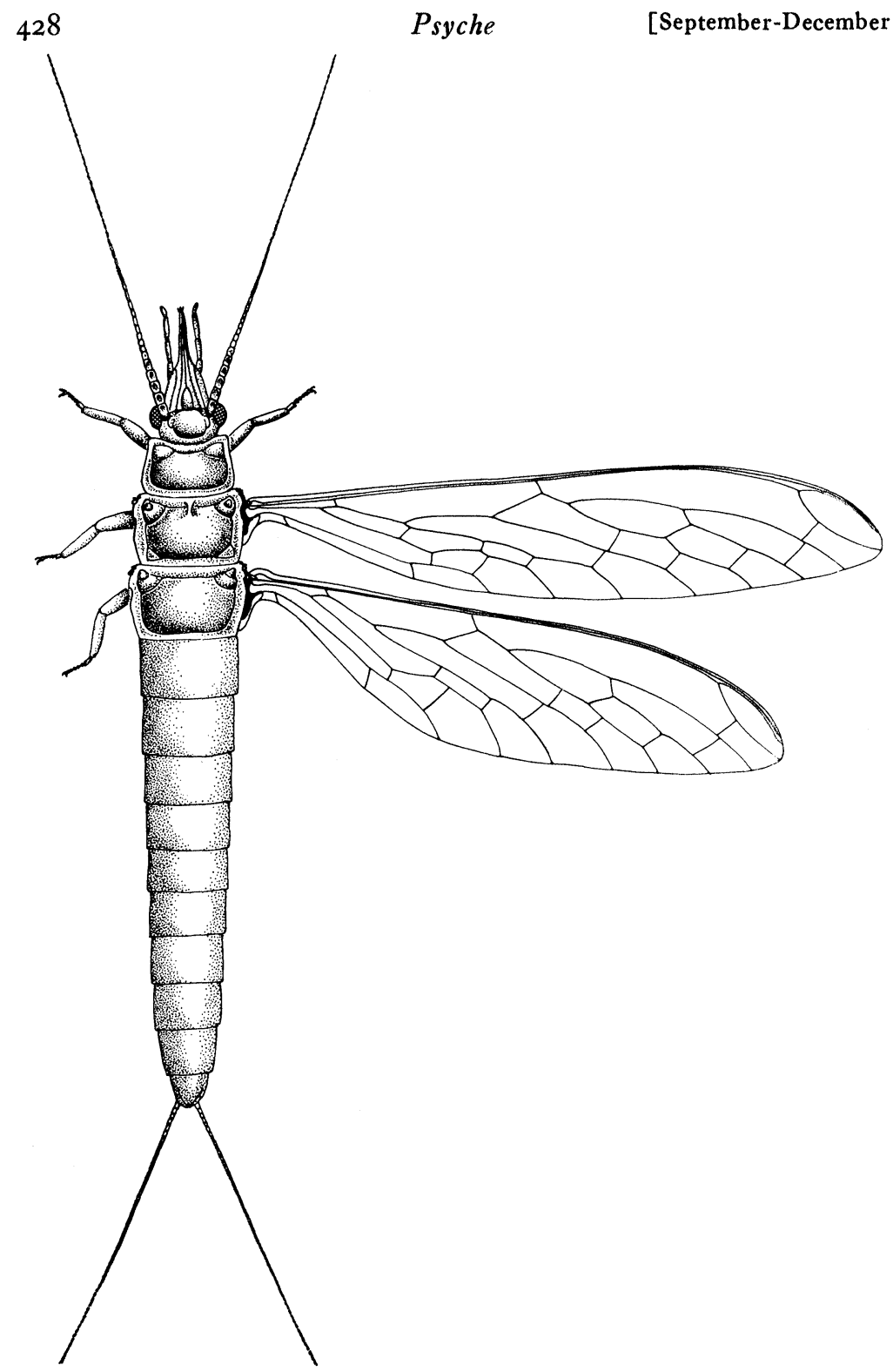

Fig. 11. Reconstruction of Protohymen (Megasecoptera, Protohymenidae). All structures shown are preserved in specimens of Protohymen permianus and $P$. readi, except for the meso- and metathoracic legs, which are restored on the basis of the prothoracic legs. Original. Lower Permian, Kansas. 


\section{SUMmary}

In the several paleopterous orders, the "axillary plates" are by no means to be considered as fully homologous structures. They are formed by fusion of various basal plates, which can eventually vary in the degree of fusion and in the individual size within a single order (for instance in Palaeodictyoptera, and in Diaphanopterodea).

There is little doubt that in the hypothetical primitive ancestor of Paleoptera the main veins originated from the separate basal plates. From this condition, the axillary plate was derived by fusion of the following plates: in Palaeodictyoptera, of subcosto-anal plates; in Ephemeroptera, of subcosto-cubital plates; in Odonata, of radioanal plates; in Diaphanopterodea, of medio-cubital plates; in Megasecoptera, only small subcostal plate remained.

In spite of the variability mentioned above, the general plan of the axillary region and adjacent part of the wings is shared by all paleopterous orders, and certain structures, functionally significant for the flight, repeat many times throughout Paleoptera. For instance, separated or semi-separated anal plates occur in Magasecoptera, Diaphanopterodea, and Ephemeroptera. A deeply concave furrow crossing transversely the anal area is found in almost all Palaeodictyoptera and in the Ephemeroptera. Transverse reinforcement of the proximal half of the wing formed by coalesced veins and supporting cross veins, cuticular thickenings and pigmented stripes is present in Odonata and in "odonatoid" (dragonfly-convergent) Palaeodictyoptera, etc. These structures will not be understood until more study of the functional morphology has been done, particularly on extant mayflies, dragonflies, and on wings in general.

\section{REFERENCES}

Brodskyi, A. K.

1970. Organisation of the Flight System of the Mayfly Ephemera vulgata L. (Ephemeroptera). Ent. Rev. Wash., 49: 184-188.

Carpenter, F. M.

1933. The Lower Permian Insects of Kansas. Part 6. Delopteridae, Protelytroptera, Plectoptera and a New Collection of Protodonata. Odonata, Megasecoptera, Homoptera, and Psocoptera. Proc. Amer. Acad. Arts \& Sci., 68 (11): 411-503.

1963. Studies on Carboniferous Insects from Commentry, France. Part V. The Genus Diaphanoptera and the Order DiaphanopНАтсн, G. terodea. Psyche, 70(4): 240-256.

1966. Structures and mechanics of the dragonfly pterothorax. Ann. Ent. Soc. Amer., 50: 702-714. 
KuKalova, J.

1960. New Palaeodictyoptera of the Carboniferous and Permian of Czechoslovakia. Sbornik UUG, 25: 236-251.

1969- Revisional Study of the Order Palaeodictyoptera in the Upper

1970. Carboniferous Shales of Commentry, France. Part 1. Psyche, $76(2): 163-215$; Part 2. Psyche, 76(4) : 439-486; Part 3. Psyche, $77(1): 1-44$.

Kukalova-Peck, J.

1971. The Structure of Dunbaria (Palaeodictyoptera). Psyche, 78(4): 306-318.

1974. Wing-folding in the Paleozoic Insect Order Diaphanopterodea (Paleoptera), with a Description of New Representatives of the Family Elmoidae. Psyche, 81(2): 315-333.

Matsuda, R.

1970. Morphology and Evolution of the Insect Thorax. Mem. Ent. Soc. Can. 76: 3-431.

Neville, A. C.

1960. Aspects of Flight Mechanics in Anisopterous Dragonflies. J. Exp. Biol., 37: 631-656.

Sharov, A. G.

1971. Morphological Features and the Way of Life of Palaeodictyoptera. Dokl. 24. tschtenii pam. N.A. Cholodkovskogo. Akad. Nauk SSSR, Moscow: 49-63.

TANNERT, W.

1958. Die Fluegelgelenkung bei Odonaten. Deutsche Ent. Zeitschr., (N.F.), $5(5): 394-455$.

Tschernova, O. M.

1965. Some Fossil Mayflies (Ephemeroptera, Misthodotidae) found in Permian Deposits in the Ural Mountains. Ent. Rev. Wash., 44: 202-207.

Tsui, T. P. and W. L. Peters

1972. The Comparative Morphology of the Thorax of Selected Genera of the Leptophlebiidae (Ephemeroptera). J. Zool., Lond., 168: 309-367.

Wootron, R. J.

1972. Nymphs of Palaeodictyoptera (Insecta) from the Westphalian of England. Palaeontology, 15: 662-675. 

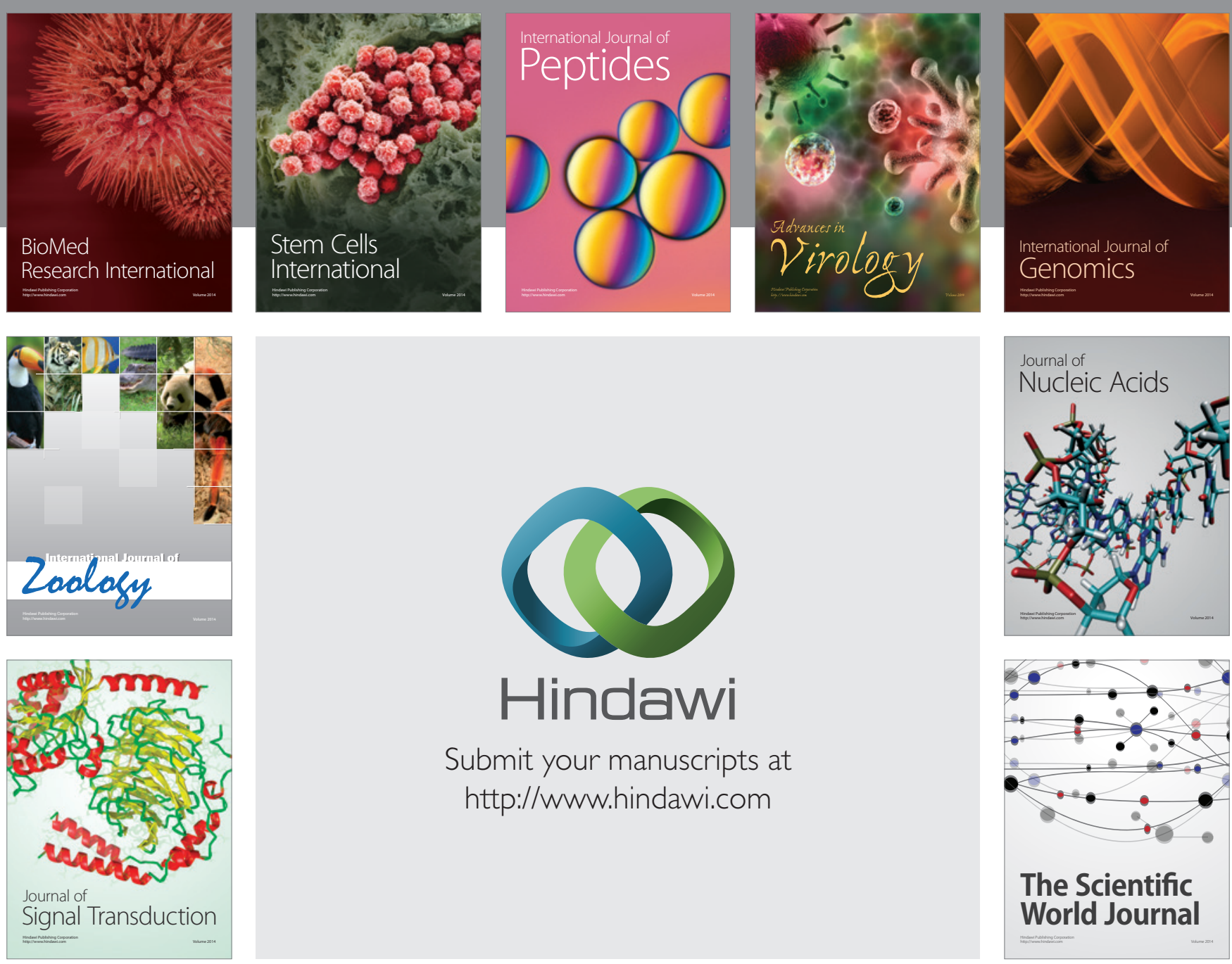

Submit your manuscripts at

http://www.hindawi.com
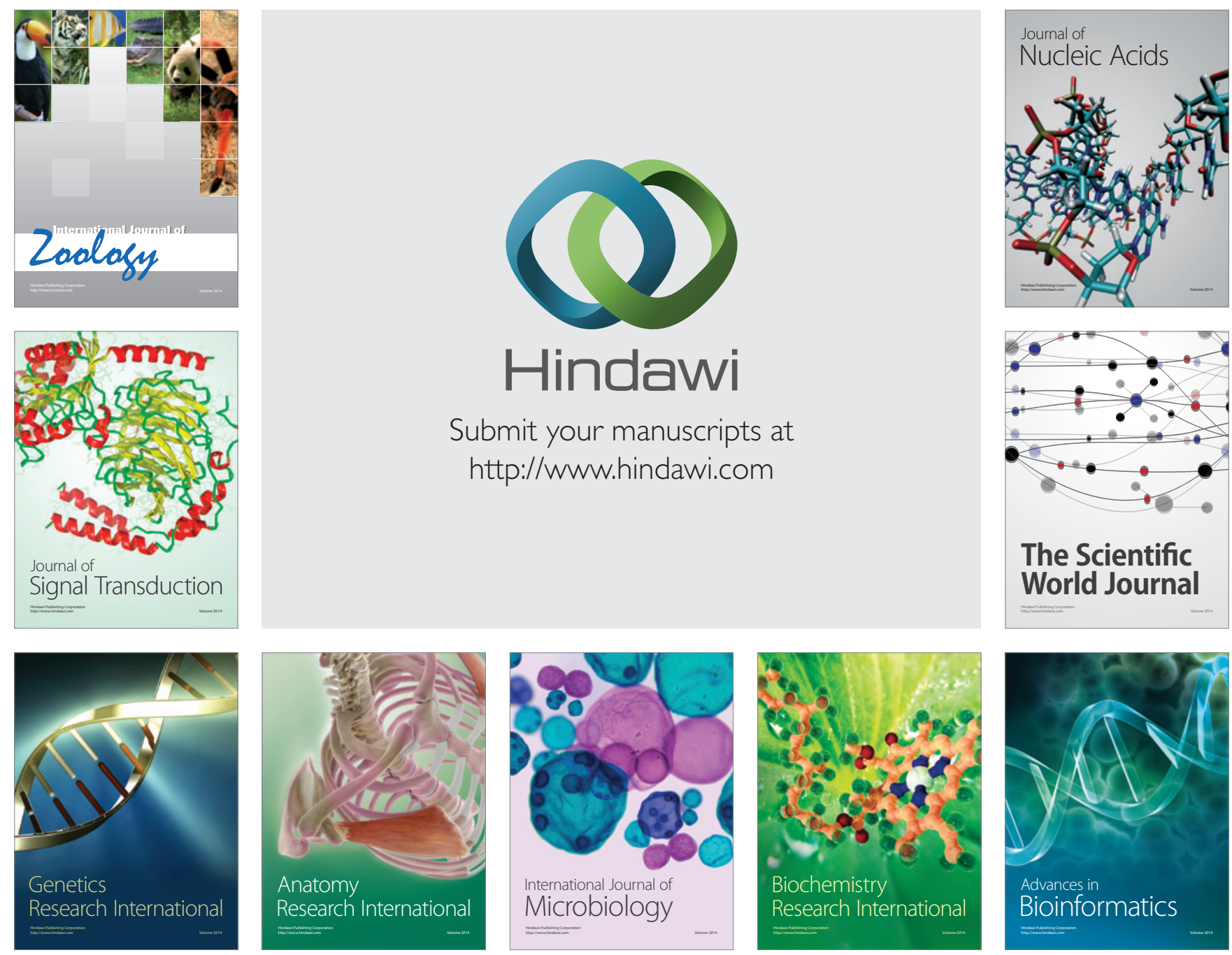

The Scientific World Journal
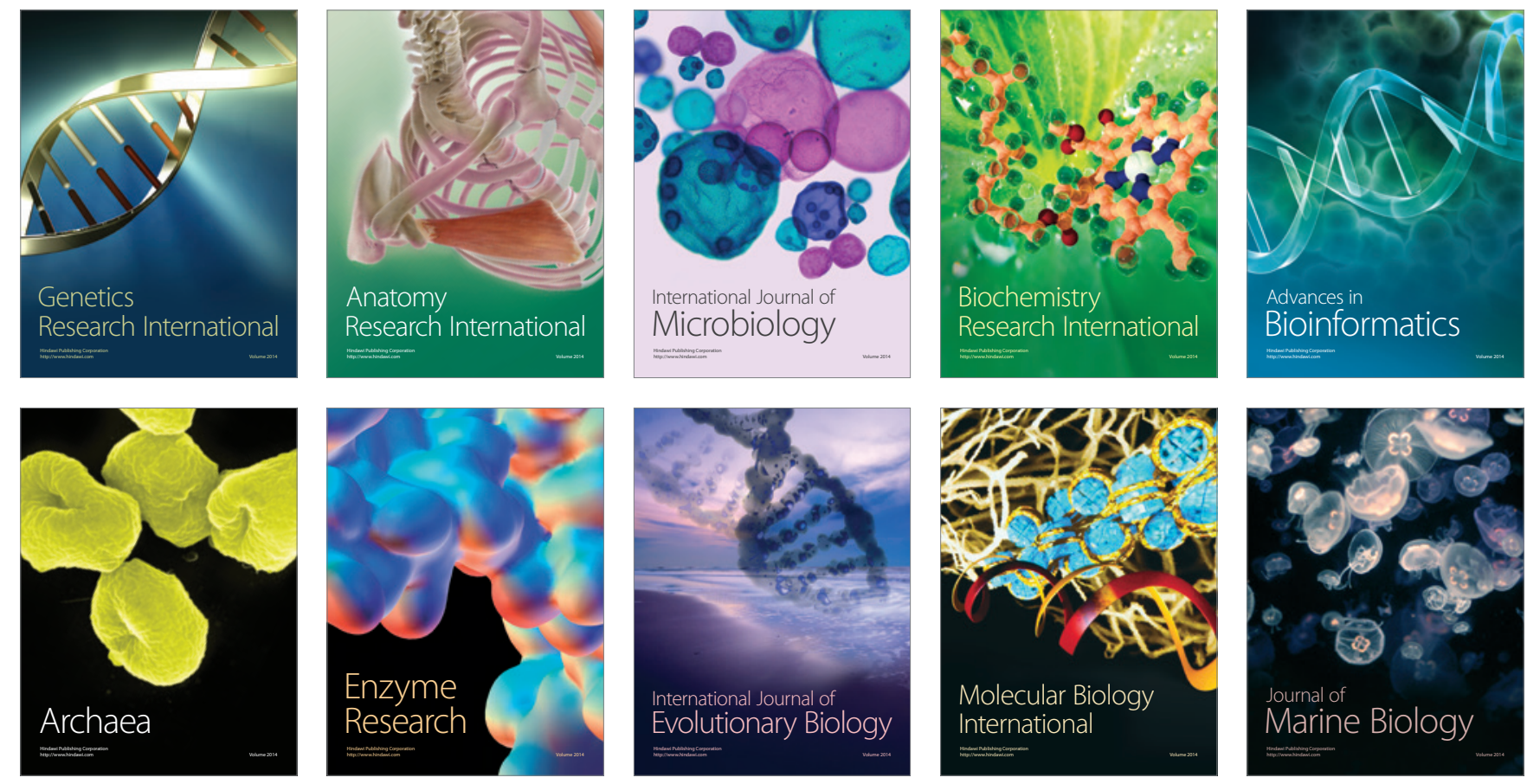